\title{
Recent warming trends inferred from borehole temperature data in Figuig area (Eastern Morocco)
}

\author{
Lalla Amina Ouzzaouit $^{\mathrm{a}, *}$, Alae Bakraoui ${ }^{\mathrm{b}}$, Nouredine Benalioulhaj ${ }^{\mathrm{c}}$, Julio Carneiro ${ }^{\mathrm{d}}$, Antonio Correia ${ }^{\mathrm{e}}$, \\ Abdelhakim Jilali ${ }^{\mathrm{b}}$, Abdelkrim Rimi ${ }^{\mathrm{a}}$, Yassine Zarhloule ${ }^{\mathrm{b}}$ \\ a University Mohammed V - Agdal, Scientific Institute, Rabat, Morocco \\ ${ }^{\mathrm{b}}$ Laboratory of Hydrogeology-Environment, Faculty of Sciences, University Mohamed Ist, Oujda, Morocco \\ 'University Mohammed V - Agdal, Ecole Mohammadia d'Ingénieurs, Avenue Ibnsina B.P. 765, Agdal, Rabat, Morocco \\ ${ }^{\mathrm{d}}$ Department of Geosciences, Geophysical Centre of Évora, University of Évora, Portugal \\ e Department of Physics, Geophysical Centre of Évora, University of Évora, Portugal
}

\section{A R T I C L E I N F O}

Article history:

Received 29 August 2013

Received in revised form 4 March 2014

Accepted 7 March 2014

Available online 2 April 2014

\section{Keywords:}

Climate change

Borehole temperature

Geothermal gradient

Eastern Morocco

\begin{abstract}
A B S T R A C T
Ground surface temperature history (GSTH) reflecting the past climate conditions in eastern Morocco was evaluated by analyzing the temperature-depth profiles measured in four boreholes at the Figuig Oasis. The temperature-depth data were inverted using the functional space inversion method in order to reconstruct the surface temperature past changes. The results reveal a recent warming in the last century with an amplitude of $1-3^{\circ} \mathrm{C}$ for the four boreholes and a comparison with surface air temperature (SAT) variation from the Bouarfa and Bechar meteorological stations confirms this result. This warming trend is confirmed by other climate proxies.
\end{abstract}

(c) 2014 Elsevier Ltd. All rights reserved.

\section{Introduction}

Meteorological records are considered as the most reliable source of information for assessing the climate change patterns through time. However, those data suffer from the relatively short time span of registration, which makes them less adequate to identify long-term trends and for comparison with historical times previous to the onset of registration. Therefore, other indirect methods are often used to cover spatial and temporal gaps. In recent year, geothermal logs have been used to reconstruct ground surface temperature histories (GSTH) (Nielsen and Beck, 1989; Vasseur and Mareschal, 1993; Dahl-Jensen et al., 1998; Correia and Safanda, 1999; Safanda and Rajver, 2001; Correia and Safanda 2001). Actually, temperature logs obtained by a precise temperature logging in boreholes can be used to reconstruct climate history over several past centuries. Recent climate changing (warming or cooling) detected in most of the temperature logs obtained in boreholes all over the globe is related with changes in the energy budget at the Earths surface which result from an increasing or decreasing of the atmosphere temperature. The variations of the temperature at the surface of the earth penetrate into the sub-

\footnotetext{
* Corresponding author. Tel.: +212 669441408.

E-mail address: aminaouzzaouit@gmail.com (L.A. Ouzzaouit).
}

surface, with the high-frequency component of the temperature signal progressively filtered out. Therefore, the temperature field at depths that range from tens to several hundreds of meters contains valuable information on the history of the long term ground surface temperature without the effect of short-term variations.

The principle of the method is simple; the mean temperature fluctuations on the ground surface is reflected on the subsurface temperature with a time lag" and attenuation. Assuming conductive transfer in a homogeneous medium, the heat equation is written as:

$\frac{\partial T}{\partial t}=\alpha \frac{\partial^{2} T}{Z^{2} \partial}$

where $T$ is the temperature, $t$ is time, $z$ is the depth and $\alpha$ is the thermal diffusivity of the medium.

If the surface temperature is stable and the medium is homogeneous, the distribution of the temperature below surface $(T)$ varies linearly with depth and the surface temperature $\left(T_{0}\right)$ can be obtained by extrapolation from the temperature-depth profile. The initial conditions at $t=0$, can be written as:

$T(z, 0)=T_{0}+G_{0} z$

where $G_{0}$ is the geothermal gradient. 
Following an instantaneous surface warming or cooling, the change of temperature is propagated in depth and the temperature profile is modified. The extrapolation of the linear trend to the surface can be used to estimate the warming.

The effect of the past climate changes on the variation in temperature was recognized by the first researchers in terrestrial heat flow (Lane, 1923; Hotchkiss and Ingersoll, 1934) and its general mathematical formulation, discussed in detail by Carslaw and Jaeger (1962) is

$T(z, t)=T_{0}+G_{0}+\Delta T^{*} \operatorname{erfc}\left(\frac{z}{z \sqrt{\alpha \Delta t}}\right)$

where erfc is the complementary error function and $\Delta T^{*}$ is the ground surface temperature (GST) variation and $\Delta t$ is the time span.

Inversions of borehole temperature measurements to retrieve GSTH have been conducted in many regions of the world, from America to Europe Asia and Africa. However in northern Africa, except for Morocco, this method has not been widely applied.

This article describes an application of this technique to the Figuig region in East Morocco, an oasis located near the MoroccanAlgerian border, at the edge of the Sahara desert. Figuig, as any oasis, is highly dependent on groundwater resources, and throughout the years a number of boreholes have been drilled to meet the need of groundwater demand. Borehole temperature measurements were carried out and temperature profiles inverted to detect climate change effects. The article first describes the study area and the thermal datasets collected. Then, it addresses the results of the temperature inversion and discusses them also in relation to climate proxies.

\section{Study area and datasets}

The study of the past climate in Morocco using geothermal data started in 2000. Rimi (2000) selected 10 boreholes temperature logs for estimating past GSTH. The results indicated a warming of approximately $1.5-3{ }^{\circ} \mathrm{C}$ over the last $100-300$ years. In northeastern Morocco, Barkaoui et al. (2012) recently processed two thermal profiles for estimating the ground surface temperature history and obtained a warming by $0.1-1^{\circ} \mathrm{C}$ in last century. This conclusion agrees with the results obtained from the analysis of air temperature records at the Oujda meteorological station.

In this paper we present a new reconstruction of the past climate change in the Figuig oasis, located at the eastern end of the High Eastern Atlas of Morocco. Figuig is characterized by a Saharan arid climate, hot in the summer and cold in the winter. Structurally, the Figuig area consists of a massif having an anticline structure (Fig. 1). The two anticlines of Jbel Grouz, and Jbel Maïz are separated by the Tisserfine plain and the synclinal of Figuig. The anticlines are primarily composed by Lower to Middle Liassic limestone, while the syncline comprises Liassic limestones and Bajocien sandstone. To the South, the Southern Atlasic fault puts into contact the Bajocian with Cretaceous formations.

The temperatures were measured with an ANTARES temperature datalogger, in 4 groundwater boreholes (designated as 279$50,293-50,433-50$, and 291-50), that reach a maximum depth of $800 \mathrm{~m}$.

Figs. 2-5 show the lithological logs and temperature records obtained in the four boreholes.

Borehole 279-50 is composed, from top to bottom, by a thin alluvium cover over a layer of limestone $50 \mathrm{~m}$ thick, and interlayered red clays and marls. From $60 \mathrm{~m}$ to the total borehole depth

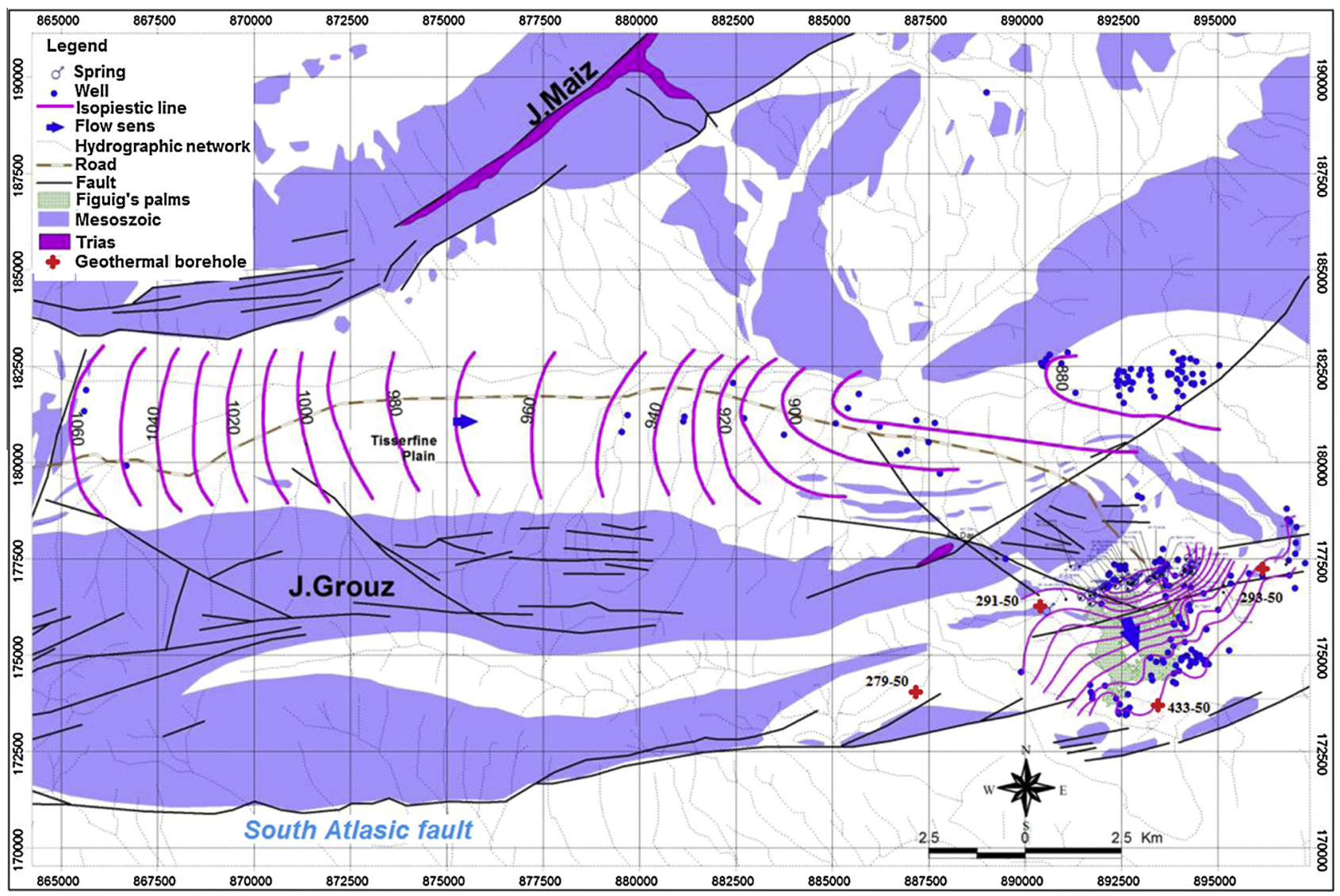

Fig. 1. Hydrogeological sketch of Figuig area (after Amar et al., 2012), showing the locations of the boreholes studied for ground surface temperature history. 

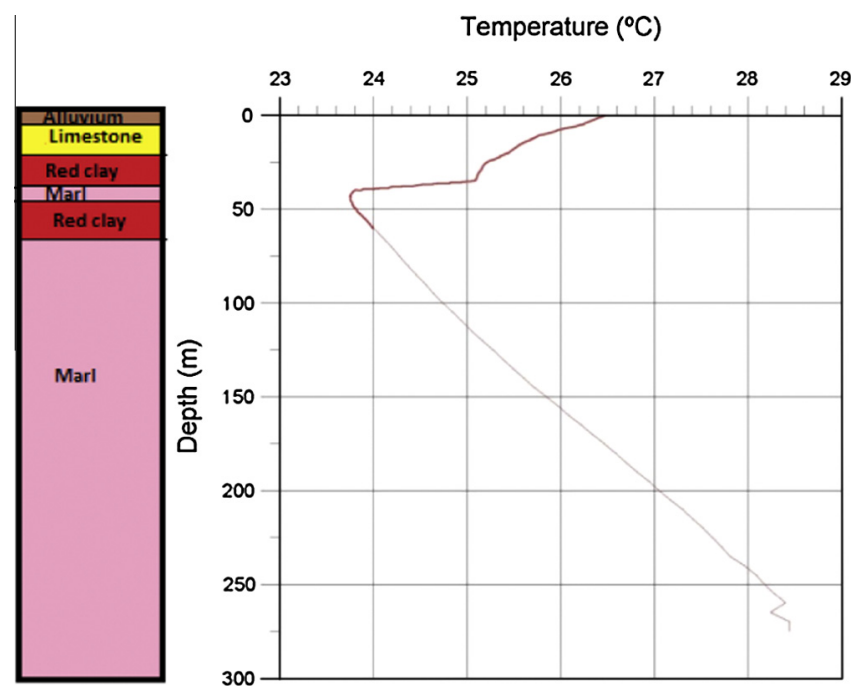

Fig. 2. Thermal profile in borehole 279-50 .The gradient increases in the depth $60 \mathrm{~m}$ on the level of the marl. The section in red indicates the range of temperaturedepth log used for inversion.

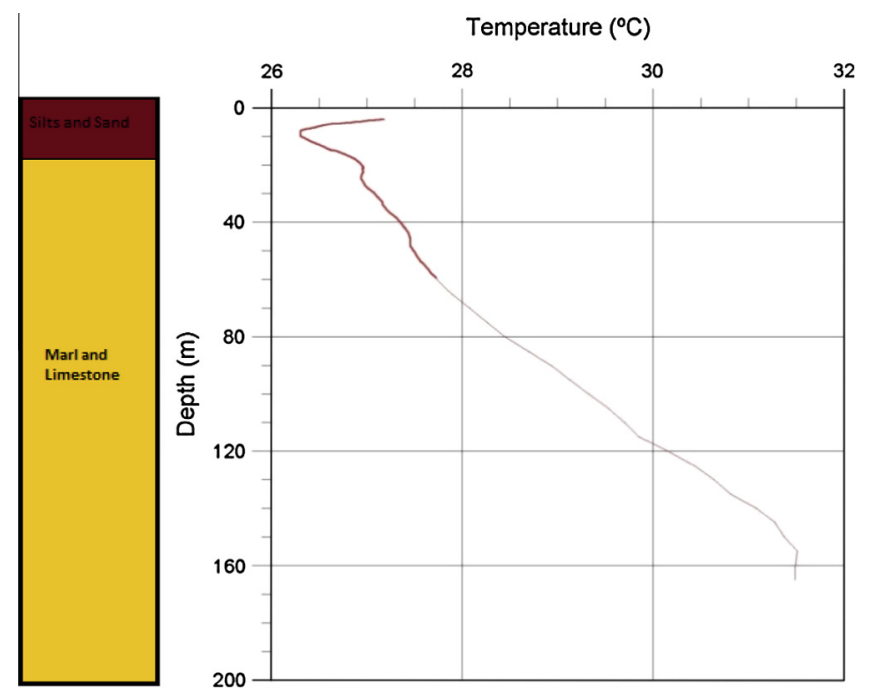

Fig. 3. Thermal profile in borehole $293-50$.The gradient increases in the depth $60 \mathrm{~m}$ on the level of the marl and limestone. The section in red indicates the range of temperature-depth log used for inversion.

(373 $\mathrm{m}$ ), the borehole intercepted a thick sequence of marls. Measurements started at $0 \mathrm{~m}$ depth and proceeded at $5 \mathrm{~m}$ increments down to $40 \mathrm{~m}$ depth, after which the increments were of $2 \mathrm{~m}$ as far as $275 \mathrm{~m}$.

In the borehole 293-50 the lithology is silty and sandy in the first $20 \mathrm{~m}$, followed by marl and limestone. Measurements started at $8 \mathrm{~m}$ depth and proceeded at $2 \mathrm{~m}$ increments down to $60 \mathrm{~m}$ depth, after which the increments were of $5 \mathrm{~m}$ as far as $165 \mathrm{~m}$.

In the borehole 433-50 the lithological log is formed by interlayered marl and conglomerate, followed by gravels at the bottom of the borehole. Measurements started at $12 \mathrm{~m}$ depth and proceeded at $2 \mathrm{~m}$ increments down to $60 \mathrm{~m}$ depth, after which the increments were of $5 \mathrm{~m}$ as far as $370 \mathrm{~m}$.

In the borehole 291-50 the lithological log is formed by limestone followed by marl and limestone. Measurements started at $8 \mathrm{~m}$ depth and proceeded at $2 \mathrm{~m}$ increments down to $60 \mathrm{~m}$ depth, after which the increments were of $5 \mathrm{~m}$ as far as $360 \mathrm{~m}$.

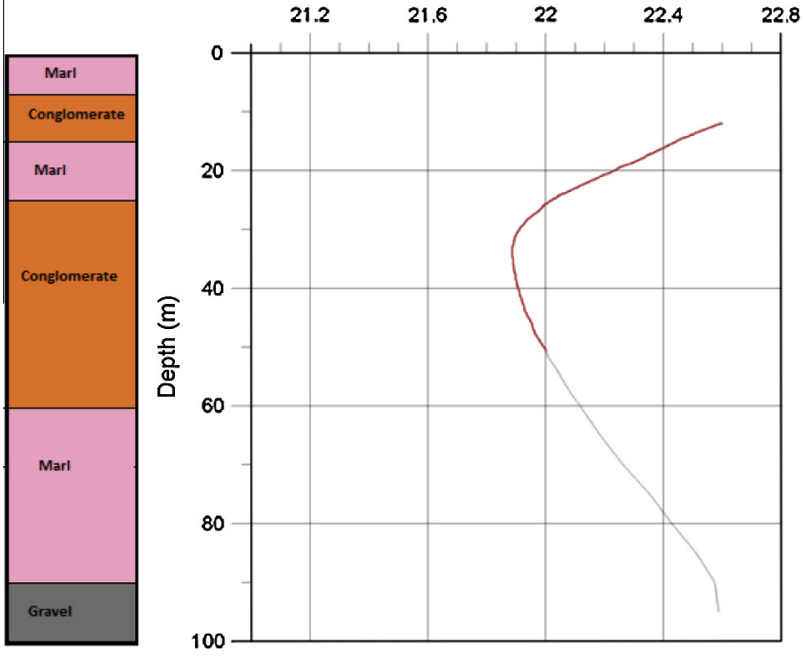

Fig. 4. Thermal profile in borehole 433-50. The gradient increases in the depth $50 \mathrm{~m}$ on the level of the conglomerate. The section in red indicates the range of temperature-depth log used for inversion.

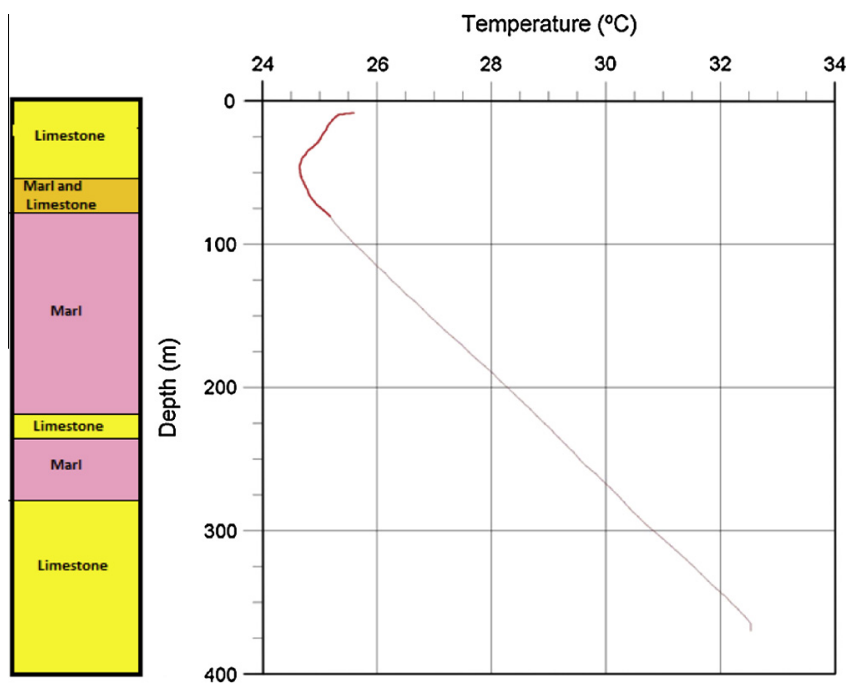

Fig. 5. Thermal profile in borehole 291-50 .The gradient increases in the depth $80 \mathrm{~m}$ on the level of the marl. The section in red indicates the range of temperaturedepth log used for inversion.

\section{Results}

Table 1 shows the results of temperatures measurements and geothermal gradient estimates.

In order to reconstruct the GSTH the functional space inversion FSI method was applied (Shen and Beck, 1991, 1992). Similarly to other inversion techniques, the FSI method assumes that heat transfer occurs only by conduction through a one-dimensional medium.

The method requires a priori estimates of the GST variations, which in this study were assumed to be zero. The thermo-physical parameters of the model are processed as random quantities defined by a priori estimates of their values and their standard deviations (SDs)., Fig. 6 presents result of inversions (GSTHs for each borehole) and adjusted simultaneously in the course of the inversion, while their uncertainties are accounted for as a priori standard deviations (SD). This is especially important for addressing properly the possibly unrecognized steady-state noise in the 
Table 1

The results of temperatures measurements and geothermal gradient estimates.

\begin{tabular}{|c|c|c|c|c|c|c|}
\hline Borehole & $\mathrm{X}(\mathrm{m})$ & $\mathrm{Y}(\mathrm{m})$ & Piezometric level depth (m) & Depth (m) & Geothermal gradient ${ }^{\circ} \mathrm{C} / \mathrm{m}$ & Warming $\left({ }^{\circ} \mathrm{C}\right)$ since 1950 \\
\hline $279-50$ & 887342 & 173859 & 56 & 373 & 0.022 & 1 \\
\hline $293-50$ & 896058 & 177285 & 15.53 & 500 & 0.035 & 1.5 \\
\hline $433-50$ & 893488 & 173662 & 27 & 815 & 0.015 & 1.5 \\
\hline $291-50$ & 890500 & 176350 & 7.93 & 391 & 0.026 & 3 \\
\hline
\end{tabular}

measured temperature profile arising from the thermal conductivity heterogeneity (Shen et al., 1995).

Four a priori SD pairs for thermal conductivity and borehole temperatures were used; (i) $0.5 \mathrm{Wm}^{-1} \mathrm{~K}^{-1}$ and $0.05 \mathrm{~K}$; (ii) $1.0 \mathrm{Wm}^{-1} \mathrm{~K}^{-1}$ and $0.05 \mathrm{~K}$; (iii) $1.0 \mathrm{Wm}^{-1} \mathrm{~K}^{-1}$ and $0.1 \mathrm{~K}$; (iv) 2.0 $\mathrm{Wm}^{-1} \mathrm{~K}^{-1}, 0.1 \mathrm{~K}$.

The geology of the investigated site suggest that the layered structure has no important 3-D effects on the subsurface temperature field.

The FSI methods has the ability to provide reliable GSTH information consistent with air temperatures when the disturbing effects are negligible (Correia, 2009). A comparison with the surface air temperature (SAT) records is useful to evaluate the reliability of the foregoing interpretations and to which extent inversion techniques yield meaningful results.

The Figuig area climate is an arid climate with Saharan influence. The air temperatures are cold in winter (December: average minimum $=3.8^{\circ} \mathrm{C}$ ) and hot in the summer (July and August: average maximum temperature: $41.3^{\circ} \mathrm{C}$ ). The absolute extreme temperatures are $49^{\circ} \mathrm{C}$ and $4{ }^{\circ} \mathrm{C}$.

The Interannual average rainfall is about $128 \mathrm{~mm}$ but characterized by a marked irregularity (Fig. 7). According to that record the
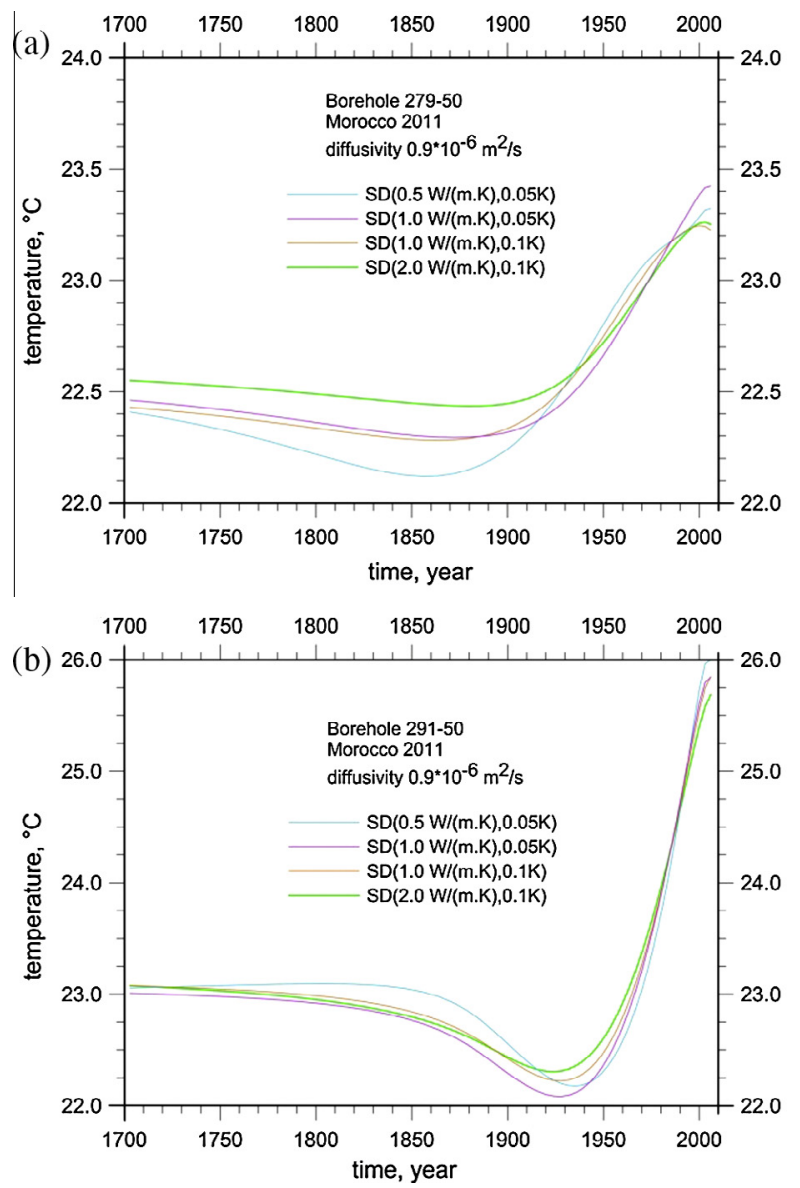

eastern Morocco region has suffered from the large (30\%) rainfall reduction since 1935 (Sebbar et al., 2011).

Several meteorological stations in the eastern Morocco region have recorded temperatures since the mid 20th century, and the average annual temperature evolution shows a significant increase. We have analyzed the trend of the air temperature at the closest Bouarfa station from Figuig area and Bechar meteorological station in Algeria (obtained at http://data.giss.nasa.gov/gistemp/). The Bechar station shows an almost continuous record since 1957, while the record in the Bouarfa station starts only in 1981, and shows an increasing trend of about $0.043^{\circ} \mathrm{C} / \mathrm{yr}$ since then. This trend is stronger than at the Bechar station which points to an average increase of only $0.028^{\circ} \mathrm{C} / \mathrm{yr}$ from 1957 . However, if we consider only the period from 1981, the trend would be of $0.05^{\circ} \mathrm{C} / \mathrm{yr}$. Notice, that previous studies in the Northeastern part of Morocco suggest an increasing temperature rate of only $0.37^{\circ} \mathrm{C} / \mathrm{yr}$ for the same period (Barkaoui et al., 2012).

The Figuig zone was also strongly affected in the 1960s by desertification following the increasing dryness and overuse of agriculture capacities. The increase of SAT in eastern Morocco correlates well with the decrease of precipitations (Fig. 8) as well as with the increase of grazing and agricultural activity. GSTH derived
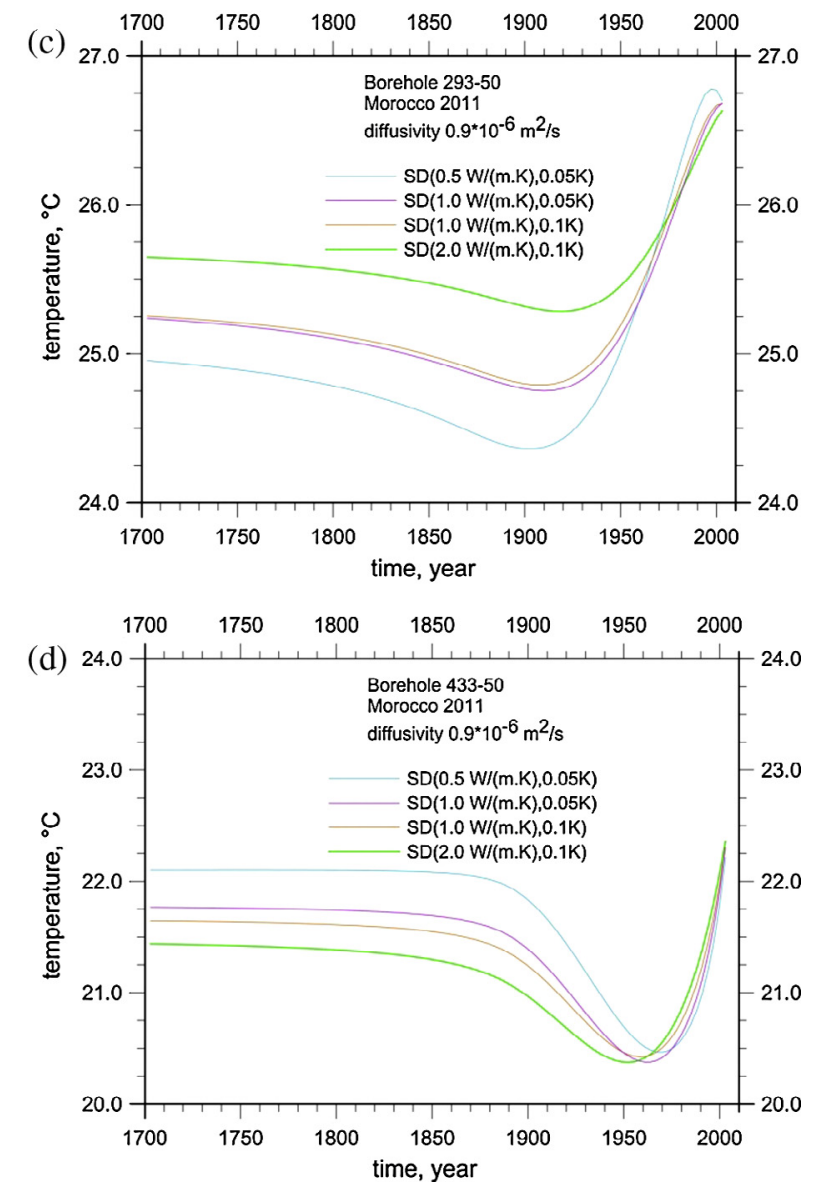

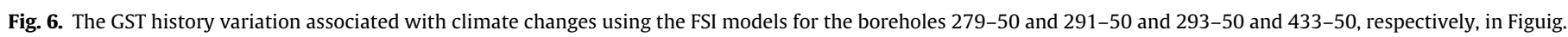




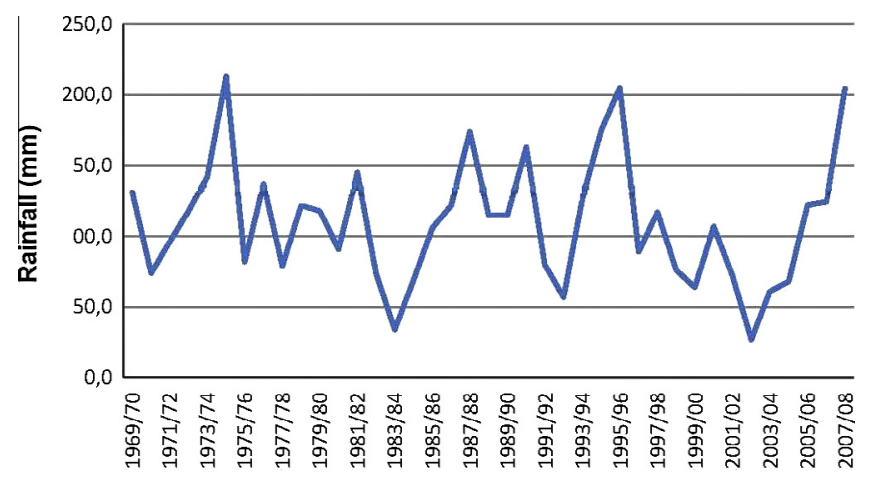

Fig. 7. Interannual rainfall variation in Figuig from 1969 to 2008 (El Hachemi, 2012).

from boreholes should therefore constrain the temperatures anomalies before SAT measurements. The estimate of the climate variability prior to the existence of the instrumental record can be also derived from climate proxies. The reconstruction of the long-term changes in the Palmer Drought Severity Index (PDSI) over the last nine centuries in northwestern Africa revealed that the latter half of the twentieth century was one of the driest in the region, (Touchan et al., 2010) (see Fig. 9).

\section{Discussion}

The GSTH reconstructed in the four boreholes show a general steady temperature increase, but with a steepest increase during the second half of the twentieth century. This acceleration is compatible with the air temperature increase recorded at the Bechar and Figuig stations since 1957 (Fig. 10), and throughout Africa since 1900 (Hulme et al., 2001). The temperature increase is also in also in agreement with isoprenoid membrane lipids and alkenone based sea surface temperature reconstructions (SST) in the Mediterranean, which revealed an increased rate of warming during the second half of the 20th century (Nieto-Moreno et al., 2013). On the other hand, all estimated GSTH reveal a clear low from 1850 to 1950 A.D. just before the recent warming period in the last 100 years; a similar observation has been done in Italia by Verdoya et al. (2007) using a joint analysis of surface air temperature series and geothermal profiles, a cooling peak in 1950 before giving way to a rapid warming; however this cooling is less striking in the borehole 279-50.
We note that the GSTH amplitude in the three boreholes 279$50,293-50$ and 433-50 is in good agreement with SAT observations recorded at Bechar meteorological station since 1957 (around $1,5^{\circ} \mathrm{C}$ ) while, the borehole $291-50$ presents a temperature increase of $3{ }^{\circ} \mathrm{C}$ during these fifty years (Table 1). Though the four boreholes are not very far from each other $(1500-8500 \mathrm{~m})$, and surface conditions remain similar with no identified recent change, these GSTH vary from one borehole to the other in terms of the amplitude and timing of the temporal variations, such a variation is more likely affected by local subsurface characteristics. Within this high landform area, interaction between underground water circulation guided by regional tectonic structures (Puigserver et al., 2006) and heat transfer could generate a hydrologic convection driven by thermal density differences or piezometric conditions (Lachenbruch and Sass, 1977). The higher perturbation recorded at borehole $291-50$ seems to be linked to ground water flow in limestone about $50 \mathrm{~m}$ thick below the surface. Located in a recharge area (Fig. 1 and Table 1 ) this fractured limestone could be the place of an infiltration of relatively cool water that may amplify the subsurface climatic signal. Like water circulation, the local effects of lithology contrast may also be non-negligible source (Kooi, 2008). Given the lack of laboratory thermal conductivity measurements, values taken from the literature were used, taking into account the type of sedimentary rocks in the region (varying from marl to conglomerate and limestone) with an assumed large standard deviation (from 0.1 to $2.0 \mathrm{Wm}^{-1} \mathrm{~K}^{-1}$ ).

Lucazeau and Roland (2012) did a simple numerical models including either the changes affecting the conductive structure or the circulation of fluids and concluded that the best model to explain the observed temperature profiles could be a combination of processes (vertical, horizontal fluid flow or thermal conductivity).

In the Figuig area, the maximum depth at which temperature is perturbed is about $80 \mathrm{~m}$, which means that only perturbations from the twentieth century are recorded. This is illustrated by the GSTH resulting from the inversion of boreholes data, which is consistent with the SAT increase observed at meteorological stations, however we could not extend the surface temperature history further in the past as it does not change significantly before 1850.

The remarkable change in the mid twentieth century is therefore more likely associated to the global warming that appears stronger in this part of Africa (Lucazeau and Roland, 2012).

Other causes have been invoked to explain the GSTH: urbanization, landscape or subsurface changes can affect the climatic signal recorded in boreholes. In north eastern Morocco, Rimi (2000)

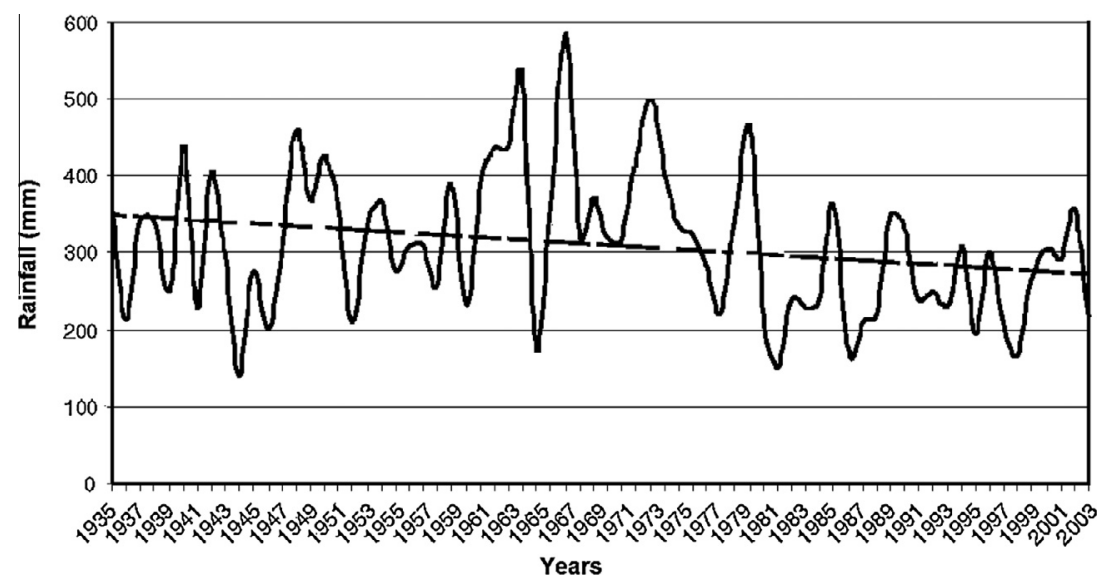

Fig. 8. Variability of annual rainfall and straight linear trend, from 1935 to 2003, at Oujda station (Sebbar et al., 2011). 


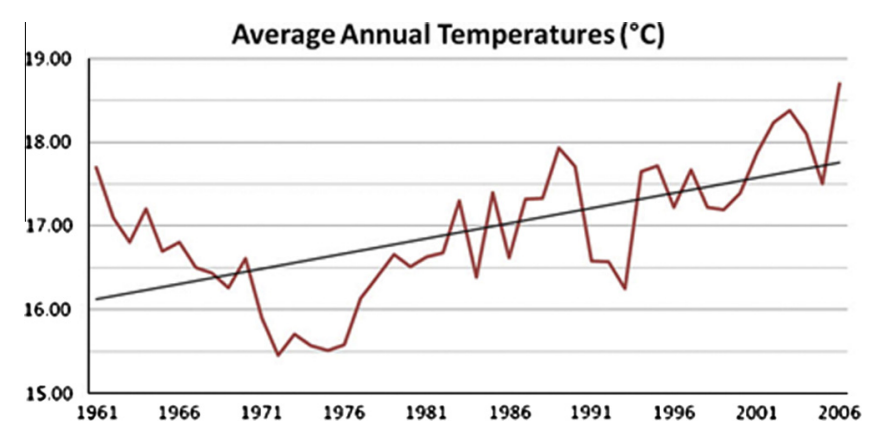

Fig. 9. Surface air temperature variation from the meteorological station of OujdaAngad (1961-2006).

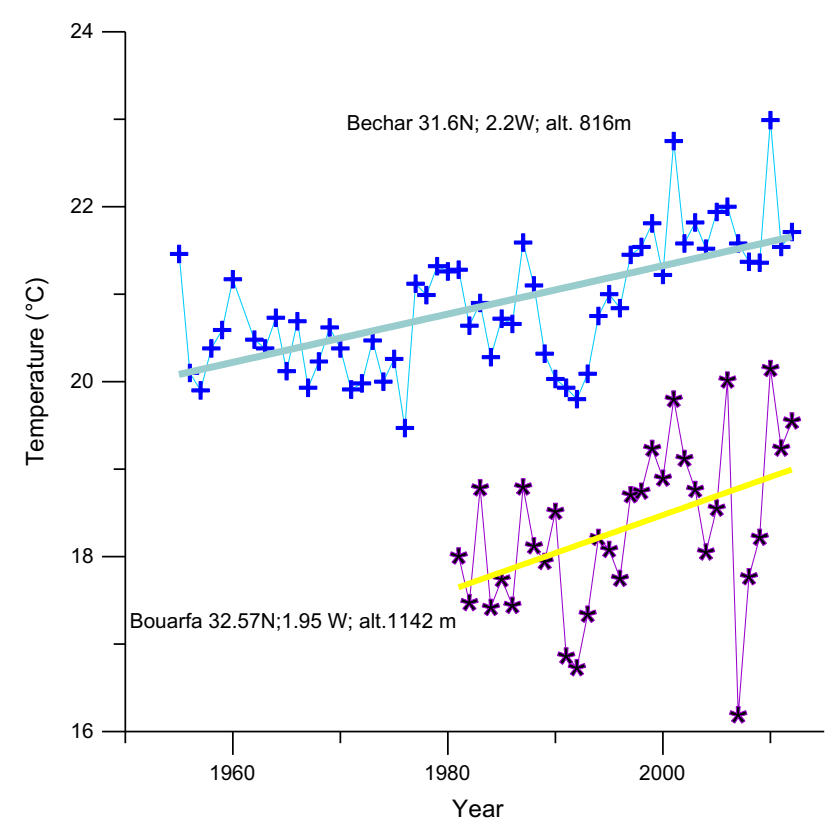

Fig. 10. Surface air temperature variation from the meteorological station of Bechar (1957-2013) and Bouarfa (1981-2012).

linked a part of the GSTH increase to deforestation and mining exploration.

Finally, the GSTH in Morocco and the rapid change in the mid twentieth century inferred from boreholes confirms the projection of IPCC for northern Africa and the Mediterranean basin (Christensen et al., 2007) as vulnerable to a temperature increase $\left(0-1.5^{\circ} \mathrm{C}\right.$ for $1906-2005$ and then from 1.5 to $4^{\circ} \mathrm{C}$ by 2100 ).

\section{Conclusions}

The results of the study presented here confirm the ability of the FSI method to provide reliable GSTH information that is consistent with air temperatures when the disturbing effects are negligible. GSTH reconstitutions obtained in the four boreholes for a diffusivity of $0.9 \times 10^{-2} \mathrm{~m}^{2} \mathrm{~s}^{-1}$ and an a priori variance of thermal conductivity of $0.1-2.0 \mathrm{Wm}^{-1} \mathrm{~K}^{-1}$ indicate a current warming trend varying from 1 to $3{ }^{\circ} \mathrm{C}$ from 1900 to 2000 . This estimated trend is coherent with the air temperature recorded at meteorological stations in Bouarfa, Oujda and Bechar. The larger GSTH increase inferred at borehole temperature 291-50 can be associated with hydrological conditions and lithological contrast. Better understanding of the relationship between soil and air temperature is needed, as well as of the effect of vegetation type, role of precipitation-evaporation and near-surface water penetration.

\section{Acknowledgements}

This research has been done in the framework of the Moroccan Portuguese program, $\mathrm{n}^{\circ}$ SDT23, GRIGES (Portugal) and CNRST (Morocco) "Les potentialités hydrogéothermiques de la nappe liasique du Maroc oriental et possibilité d'utilisation: moyenne à haute enthalpie, (University of Evora)-CNRST (University Mohammed 1st, Oujda)".

\section{References}

Amar, M., Manar, A., Boualoul, M., 2012. Apport de la cartographie aéromagnétique à l'identification structurale du système aquifère des sources de l'oasis de Figuig, Maroc. Bulletin de l'Institut Scientifique, Rabat, section Sciences de la Terre 2012 (34), 29-40.

Barkaoui, A.E., Correia, A., Zarhloule, Y., Rimi, A., Carneiro, J.F., Boughriba, M., Verdoya, M., 2012. Reconstruction of remote climate change from borehole temperature measurement in Eastern part of Morocco. J. Climatic Change, doi 10.1007/s10584-012-0638-7.

Carslaw, H.S., Jaeger, J.C., 1962. Conduction of Heat in Solids. Clarendon, Oxford, 510. Christensen, J., Hewitson, B., Busuioc, A., Chen, A., Gao, X., Held, I., Jones, R., Kolli, R., Kwon, W.-T., Laprise, R., Rueda, V.M., Mearns, L., Menéndez, C., Räisänen, J. Rinke, A., Sarr, A., Whetton, P., 2007. Regional Climate Projections. In: Climate Change 2007: The Physical Science Basis. Contribution of Working Group I to the Fourth Assessment Report of the Intergovernmental Panel on Climate Change. Cambridge University Press, Cambridge, United Kingdom and New York, NY, USA, pp. 847-940, chap. 11, 611.

Correia, A., 2009. Reconstruction of the past climate in Southern Portugal from geothermal data. In: Conf. 5th Congress of Balkan Geophysical Society, Belgrade Serbia.

Correia, A., Safanda, J., 1999. Preliminary ground surface temperature history in mainland Portugal reconstructed from borehole temperature logs. Tectonophysics 306, 269-275.

Correia, A., Safanda, J., 2001. Ground surface temperature history at a single site in southern Portugal reconstructed from borehole temperatures. Global Planet. Change 29, 155-165.

Dahl-Jensen, D., Mosegaard, K., Gundestrup, N., Clow, G.D., Johnsen, S.J., Hansen, A.W., Balling, N., 1998. Past temperatures directly from the Greenland ice sheet. Science 282, 268-271.

El Hachemi, O., 2012. Traitement des eaux usées par lagunage naturel en milieu désertique (Oasis de Figuig): Performances épuratoires et aspect phytoplanctonique. Ph.D. Thesis, Mohamed Ist Univ. Oujda, Morocco. $\mathrm{N}^{\circ}$ : 220/ $12,140$.

Hotchkiss, W.D., Ingersoll, L.R., 1934. Postglacial time calculations from recent geothermal measurments in the clumet copper mines. J. Geol. 42, 113-122.

Hulme, M., Doherty, R., Ngara, T., New, M., Lister, D., 2001. African climate change: 1900-2100. Climate Res. 17, 145-168.

Kooi, H., 2008. Spatial variability in subsurface warming over the last three decades; insight from repeated borehole temperature measurements in The Netherlands, Earth Planet. Sci. Lett. 270, 86-94.

Lachenbruch, A.H., Sass, J.H., 1977. Heat flow of the United States and thermal regime of the crust. In: Heacock, J.G. (Ed.), The Nature and Physical Properties of the Earth's Crust. American Geophysical Union Monograph, vol. 20, 626-675.

Lane, E.C., 1923. Geotherms of the Lake Superior copper county. J. Geol. 42, 113 122.

Lucazeau, F., Roland, F., 2012. Heat-flow and subsurface temperature history at the site of Saraya (eastern Senegal). Solid Earth Discuss. 4, 599-627.

Nielsen, S.B., Beck, A.E., 1989. Heat flow density values and paleoclimate determined from stochastic inversion of four temperature-depth profiles from the Superior Province of the Canadian Shield. Tectonophysics 164, 345359.

Nieto-Moreno, V.F., Martinez-Ruiza, V., Willmott, J., Garcia Orellana, Masqué, P., Sinninghe, J.S., Damsté, 2013. Climate conditions in the westernmost Mediterranean over the last two millennia: an integrated biomarker approach Organic Geochemistry 55, pp. 1-10

Puigserver, D., Carmona, J. Mª., Himi, M., Casas, A., 2006. Flow and transport mathematical modelling in order to establish the hydric resources management in the oasis of Figuig (Morocco). In: Proceedings of the 34th Congress of International Association of Hydrogeologists (IAH), October 9-13, 2006, Beijing, China.

Rimi, A., 2000. Evidence of recent warming in the north of Morocco from disturbed geothermal gradients. Geodinamica Acta 13, 19-27.

Safanda, J., Rajver, D., 2001. Signature of the last ice age in the present subsurface temperatures in the Czech Republic and Slovenia. Global Planet. Change 29, $241-257$.

Sebbar, A., Badri, W., Fougrach, H., Hsaine, M., Saloui, A., 2011. Etude de la variabilité du régime pluviométrique au Maroc septentrional (1935-2004). Sécheresse 22, 139-148. http://dx.doi.org/10.1684/sec.2009.0169.

Shen, P.Y., Beck, A.E., 1991. Least squares inversion of borehole temperature measurements in functional space. J. Geophys. 96 (19), 965-19, 979.

Shen, P.Y., Beck, A.E., 1992. Paleoclimate change and heat flow density inferred from temperature data in the Superior Province of the Canadian Shield. Global Planet. Change 6, 143-165. 
Shen, P.Y., Pollack, H.N., Huang, S., Wang, K.W., 1995. Effects of subsurface heterogeneity on the inference of climate change from borehole temperature data: model studies and field examples from Canada. Geophys. J. 100, 6383-6396. Touchan, R., Anchukaitis, K.J., Meko, D.M., Sabir, M., Attalah, S., Aloui, A., 2010 Spatiotemporal drought variability in northwestern Africa over the last nine centuries. Climatic Dyn., doi 10.1007/s00382-010-0804-4.
Vasseur, G., Mareschal, J.C., 1993. Les forages: une fenétre sur les climats passés. la recherche 24 , pp. 1076-1082.

Verdoya, M., Chiozzi, P., Pasquale, V., 2007. Thermal log analysis for recognition of ground surface temperature change and water movements. Climate Past Discuss. 3, 95-120. 